RESIDENT

\& FELLOW

SECTION

Section Editor

Mitchell S.V. Elkind,

MD, MS

Alyx Porter, MD

Address correspondence and reprint requests to Dr. Alyx Porter, Mayo Clinic, 200 1st Street SW, Rochester, MN 55905

Porter.alyx@mayo.edu

\title{
International Education Issues: A perspective on the practice of neurology in northern Kenya
}

While in residency, both my husband (a physical medicine and rehabilitation resident) and I were able to experience an international elective which has enhanced our clinical training and perspective. This elective was organized with resources from the international health program at our institution as well as World Medical Mission (WMM)/Samaritan's Purse, a nonprofit organization that places physicians in areas of need around the world. After months of preparation and endless communications with the staff of WMM, we worked at the Maua Methodist Hospital $(\mathrm{MMH})$, in northern Kenya, for 1 month. $\mathrm{MMH}$ is a medical center 6 hours north of Nairobi that serves the needs of approximately 600,000 people in the surrounding villages where the prevailing languages are English, Kiswahili, and Kimeru. Of the many patients encountered, approximately $1 / 3$ had neurologic manifestations of their disease, most often unrecognized by the local physicians.

MMH was started by British missionaries approximately 80 years ago. The hospital has grown in size and currently has approximately 300 inpatient beds which are divided into three wards (one pediatric, one medical, and one surgical). There is also an outpatient complex that serves hundreds of patients on a daily basis. The most common admitting diagnoses included HIV, tuberculosis, and malaria. By my estimation, nearly one in four hospitalized patients was HIV-positive. The hospital fees are nominal, however, most people in Maua are unemployed and the hospital fee can become an insurmountable debt. Upon admission, the patient or the next of kin must document how they intend to pay and what collateral property they have to offer. For many, the collateral included livestock. For others, the only answer given was "nil." This debt incurred has posed a major hurdle for MMH. In order to deal with this problem, patients are not dismissed from the hospital until their fees are paid. This approach, unfortunately, raises the fees further and leads to overcrowding on the wards. At the busiest time while there, three patients occupied one bed.

We were given the option of working in the outpatient setting; however, due to a staffing shortage, the inpatient service was more amenable. Each day would begin with a 30-minute hospital-wide chapel service followed by ward rounds. We performed hospital rounds on the adult medical ward from 08:00 to 13:00. We had a break for lunch and returned in the afternoon for hospital admissions. Each physician worked independently with the assistance of a medical officer (equivalent to our physician assistant) who would assist with translation if needed. We were used primarily as general physicians; however, our specialty knowledge was invaluable. I was able to recognize neurologic manifestations of HIV/ AIDS, tuberculosis, and malaria that had been undiagnosed or untreated, as well as educate the medical staff about these entities and others of neurologic origin.

The resources at $\mathrm{MMH}$ are limited. This is not only as a result of the financial means of the hospital, but also because the patients served would not be able to afford such testing and treatments. Medicine in Maua is performed with a great deal of uncertainty, and based on probability, many assumptions are made. If a patient presents with a cough, he or she had pulmonary TB until proven otherwise and were treated as such. Similarly, if a patient had a headache, fever, stomachache, and diarrhea or generally felt unwell, he or she was treated for malaria. This approach fared well most of the time due to the prevalence of these disorders.

In this setting, one must rely solely on history and clinical examination to make a diagnosis, as did our colleagues in the past. A diagnosis of atrial fibrillation or carotid stenosis as a cause for stroke was made by auscultation only, as was the presence of elevated intracranial pressure based on funduscopic examination. I evaluated patients with cord compression, spinal shock from 
trauma, acute flaccid monoparesis, amyotrophic lateral sclerosis, cerebral malaria, organophosphate poisoning, peripheral neuropathy, stroke, meningitis, encephalitis, and seizure. Unfortunately, in the majority of patients, the natural history of these illnesses prevailed due to the limitations of treatment. The investigations available were $\mathrm{x}$-ray, serum blood counts and basic metabolic panels, blood smear, CSF cell count, glucose, protein, and Gram stain.

All medications are donated to the hospital with the main source coming from Europe. We had aspirin for stroke, phenobarbital and lorazepam for seizures, quinine for malaria, amitriptyline for peripheral neuropathy, rifampin, ethambutol, acyclovir, and penicillin for meningitis/encephalitis, atropine for organophosphate poisoning, and highly active antiretroviral therapy for HIV/AIDS. Corticosteroids were limited and the only option available at the time of our visit was oral prednisone in $2 \mathrm{mg}$ tablets.

On Tuesdays we performed consultations at the Disability Community Center. This center is affiliated with the hospital and is there to serve nearly 1,800 children in the surrounding area with disabilities. We assessed children with various neurologic developmental disorders with the goal of providing diagnosis, treatment if any, and rehabilitative options. Most commonly, we evaluated children with autism and cerebral palsy, but saw other clinical syndromes consistent with phenotypes of muscular dystrophy, spinal muscular atrophy, apraxia, and hypotonia.

Specialty care is considered a luxury and is nearly inaccessible in many developing countries. Raising awareness regarding the importance of training in disorders of the central and peripheral nervous systems could have global ramifications for the field of neurology as well as for patients with neurologic diseases. This experience in Maua was invaluable for refining clinical skill as well as exposure to neurologic manifestations of many infectious diseases that are seen far less frequently in the Western world. If interested in pursuing such an experience, the first step is gaining approval by your department and investigating whether there is funding set aside for international health electives either through the department or the institution. Many institutions have partnerships with hospitals in other countries and this would be one option in choosing where to go. Another option would be contacting an organization like World Medical Mission or Doctors without Borders to see if you qualify for additional financial assistance and placement. A temporary medical license issued by the host country giving you prescribing privileges may be required and working through an organization can be very helpful to organize all of the details. A travel clinic can also be a great resource since there are various vaccinations required based on where in the world you will be traveling. An international rotation while in residency not only enhances clinical skill and perspective, but also allows you to expand the practice of neurology by sharing your knowledge with others. If allowed, the experience is highly recommended during residency and beyond. 


\title{
Neurology
}

\author{
International Education Issues: A perspective on the practice of neurology in northern \\ Kenya \\ Alyx Porter \\ Neurology 2007;69;1719-1720 \\ DOI 10.1212/01.wnl.0000285101.21666.f5
}

This information is current as of October 22, 2007

\section{Updated Information \&} Services

\section{Citations}

\section{Subspecialty Collections}

Permissions \& Licensing

Reprints including high resolution figures, can be found at: http://n.neurology.org/content/69/17/1719.full

This article has been cited by 2 HighWire-hosted articles: http://n.neurology.org/content/69/17/1719.full\#\#otherarticles

This article, along with others on similar topics, appears in the following collection(s):

Training-international

http://n.neurology.org/cgi/collection/training_international

Information about reproducing this article in parts (figures,tables) or in its entirety can be found online at:

http://www.neurology.org/about/about_the_journal\#permissions

Information about ordering reprints can be found online:

http://n.neurology.org/subscribers/advertise

Neurology ${ }^{\circledR}$ is the official journal of the American Academy of Neurology. Published continuously since 1951, it is now a weekly with 48 issues per year. Copyright . All rights reserved. Print ISSN: 0028-3878. Online ISSN: 1526-632X.

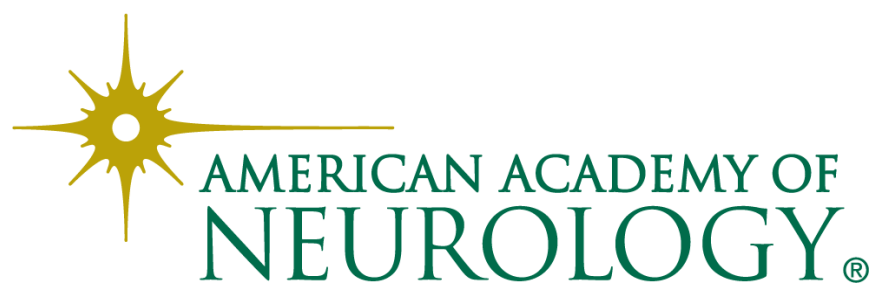

